\title{
Idiopathic Pulmonary Hypertension Induced Thrombocytopenia - A Case Report
}

\author{
Sananta Kumar Dash*, Venugopal Kulkarni, Rajendra Kumar Sahoo, Gopi Macherla and Ravikiran M
}

Department of Anesthesia and Critical Care Medicine, Citizens Hospitals and American Oncology Institute, Hyderabad, India

\begin{abstract}
Idiopathic pulmonary hypertension $(\mathrm{PH})$ is a diagnosis of exclusion for any patient presenting with pulmonary hypertension $(\mathrm{PH})$. Patient with $\mathrm{PH}$ may present with thrombocytopenia along with other signs of $\mathrm{PH}$. We report a case of $\mathrm{PH}$ who presented with thrombocytopenia and breathlessness. The possible causes of thrombocytopenia were evaluated and excluded prior to concluding that her thrombocytopenia is due to $\mathrm{PH}$. Various pathogenic mechanisms have been described for thrombocytopenia associated with $\mathrm{PH}$.
\end{abstract}

Keywords: Idiopathic pulmonary hypertension; Thrombocytopenia; Primary respiratory alkalosis

\section{Introduction}

Idiopathic $\mathrm{PH}$ is a rare but potentially fatal disease. Multiple pathogenic mechanisms have been described for thrombocytopenia in patients with $\mathrm{PH}$.

\section{Case Report}

A 46 year female who was diagnosed to have carcinoma of the breast presented with progressive breathlessness to a state of New York Heart Association functional class IV over 15 days. She was hypotensive $(90 / 64 \mathrm{mmHg})$ and hypoxic $\left(\mathrm{SpO}_{2} 88 \%\right.$ on room air) on presentation. Initial resuscitation with $500 \mathrm{ml}$ of crystalloid and high flow oxygen with a non-rebreathing mask was done. On clinical evaluation the positive findings included a raised jugular venous pressure (JVP), a loud pulmonary component of second heart sound (P2), pan systolic murmur in tricuspid area and clear lung fields on auscultation. There was no organomegaly and no clinical findings suggestive of deep venous thrombosis. Laboratory investigations revealed thrombocytopenia (platelet counts $38000 / \mathrm{cc})$, raised D Dimer $(1.5 \mu \mathrm{g} / \mathrm{ml}$, normal $<0.5$ $\mu \mathrm{g} / \mathrm{ml}$ ), primary respiratory alkalosis in arterial blood gas analysis, prominent common pulmonary and right pulmonary artery on X-ray chest anterior-posterior view. The electrocardiogram (ECG) showed $\mathrm{Q}$ wave and inverted $\mathrm{T}$ wave in lead III. Immediate computerized tomographic pulmonary angiography (CTPA) ruled out any major thromboembolic event, mediastenal compression or mass. A prominent common pulmonary artery (diameter $2.97 \mathrm{~cm}$ ) (Figure 1) and a dilated RV was marked on CT scan (Figure 2). A two dimension transthoracic echocardiography (2D Echo) showed a dilated right atrium (RA) and right ventricle (RV) and Doppler showed moderate to severe tricuspid regurgitation with a peak velocity of $3.8 \mathrm{~m} / \mathrm{s}$. A triple lumen catheter was inserted in the right internal jugular vein and the central venous pressure reading was $21 \mathrm{mmHg}$ which estimated the right ventricular systolic pressure to be $81 \mathrm{mmHg}$. A working diagnosis of idiopathic pulmonary hypertension was made after exclusion of possible differential diagnoses and treatment with Sildenafil (50 mg orally twice daily) and Bosentan (62.5 mg orally twice daily) started. She received a transfusion of single donor platelet (as the platelet count dropped further to $20000 / \mathrm{cc}$ ). She became progressively more dyspnoeic and hypotensive. Vasopressor (Noradrenaline) and inotrope (Dobutamine) were started and dose titrated to maintain a mean arterial blood pressure around $65 \mathrm{mmHg}$. She was stable for the next three hours after which she complained of worsening breathlessness, became irritable and disoriented. The heart rate suddenly dropped to $40 / \mathrm{min}$ with no palpable pulse. Cardiopulmonary resuscitation was started, her trachea was intubated and ventilated with $100 \%$ oxygen. The endotracheal suction showed frank hemorrhage and the rhythm was now asystole.

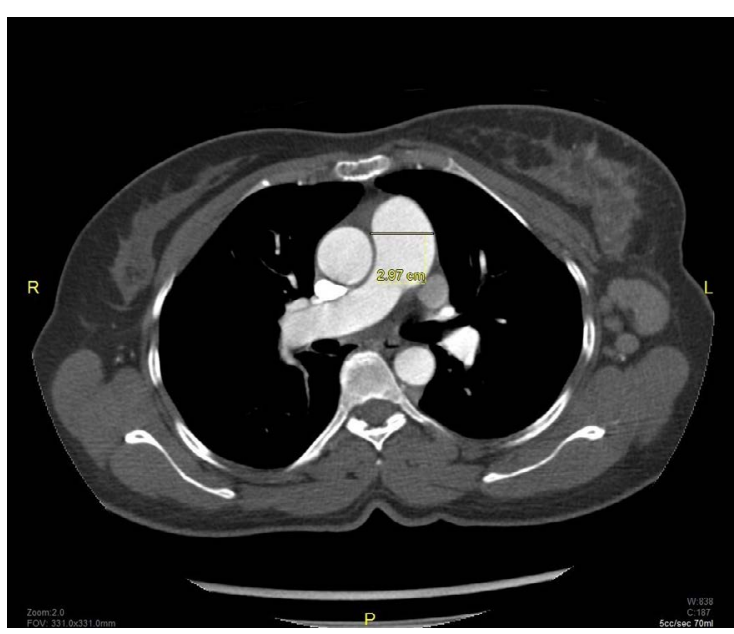

Figure 1: Prominent pulmonary artery in CTPA.

There was no response to all the resuscitation efforts and we were not able to revive her.

\section{Discussion}

Our patient could be categorized as Idiopathic pulmonary hypertension (previously categorized as Primary Pulmonary Hypertension $(\mathrm{PPH})[1,2]$. Idiopathic $\mathrm{PH}$ is a rare disease, with varying incidence from 1 to 5.9 cases per million population. Twelve percent of the diagnosed cases are inherited as autosomal dominant [3].

In a cohort study including 576 patients of $\mathrm{PH}$ of various etiology, 307 (53\%) died during follow-up (the median follow-up time was 3.9 years). The reported 1,3 and $5 \mathrm{yr}$ survival rates for the $\mathrm{PH}$ were 86,69 and $61 \%$, respectively [4].

Differential diagnosis considered were medical conditions

*Corresponding author: Sananta Kumar Dash, MD, FNB (Critical Care Medicine), EDIC, FCCP, Department of Anesthesia and Critical Care Medicine Citizens Hospitals and American Oncology Institute, Hyderabad, India, Tel: +919963322755; E-mail: drsananta@yahoo.co.in

Received May 12, 2014; Accepted February 29, 2016; Published March 03, 2016

Citation: Dash SK, Kulkarni V, Sahoo RK, Macherla G, Ravikiran M (2016) Idiopathic Pulmonary Hypertension Induced Thrombocytopenia - A Case Report. J Pulm Respir Med 6: 322. doi:10.4172/2161-105X.1000322

Copyright: @ 2016 Dash SK, et al. This is an open-access article distributed under the terms of the Creative Commons Attribution License, which permits unrestricted use, distribution, and reproduction in any medium, provided the original author and source are credited. 


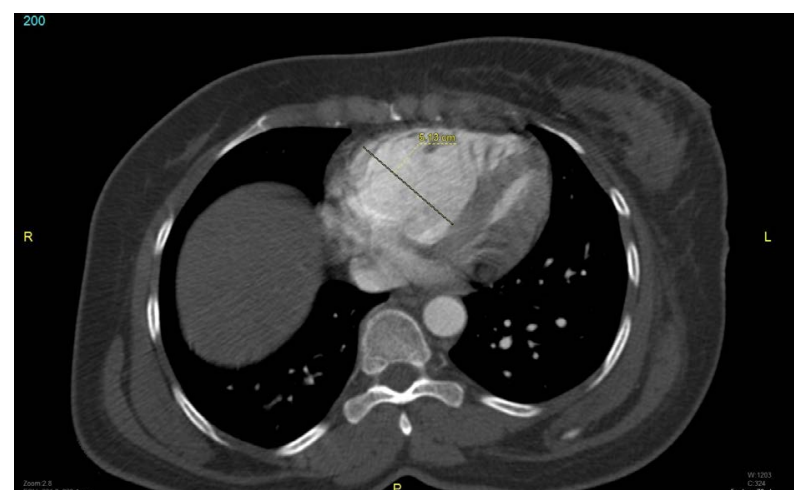

Figure 2: Dilated RV compressing into LV.

associated with PH (including portal hypertension, [5] and connective tissue disease (most commonly systemic sclerosis) [6]. Other possible etiologies considered include human immunodeficiency virus infection [7], chronic hemolytic anemias [8], and congenital heart disease (Eisenmenger syndrome). The diagnosis of idiopathic $\mathrm{PH}$ was made by careful exclusion of the above possibilities by detailed clinical history, family history, clinical examinations and specific laboratory parameters.

Pathology behind the worse outcome in $\mathrm{PH}$ includes the following. $\mathrm{RV}$ is a thin walled chamber structured to handle a low pressure pulmonary circulation $[9,10]$. Unlike the normal physiology, in $\mathrm{PH}$ the perfusion to the RV is gradually restricted only to diastole with the progression of severity of $\mathrm{PH}$ resulting in progressive ischemia and failure of RV [11]. Though there may be a disparity of $10-20 \mathrm{mmHg}$ of PASP measurement invasively as compared to 2D Echo, the latter is the preferred initial modality to diagnose, quantify and follow-up PH [12].

Expert panel recommends invasive measurement of pulmonary artery systolic pressure (PASP) as the gold standard but feasibility in each case needs evaluation [13].

In our case $\mathrm{PH}$ was diagnosed and quantitated by $2 \mathrm{D}$ Echo.

The recommendations for the use of Pulmonary vasodilators (Sildenafil and Bosentan) are restricted to WHO group I pulmonary hypertension (i.e., primary $\mathrm{PH}$ or idiopathic $\mathrm{PH}$ ) probably because, this is the most commonly studied group in clinical trials [14].

The recommended therapies for PH fall into 3 classes of pulmonary vasodilators: phosphodiesterase- 5 inhibitors, endothelin receptor antagonists, and prostacyclin analogues. The appropriate choice of the agent should be made judiciously as an erroneous administration of vasodilators in pulmonary venous hypertension may lead to worsening of venous pressure and possible pulmonary edema [14].

Mortality in $\mathrm{PH}$ is directly related to RV dysfunction. Hence optimal management of RV dysfunction in all subsets of $\mathrm{PH}$ is important. $\mathrm{PH}$ with chronic right heart failure is managed by diuresis, sodium and water restriction. Aggressive fluid resuscitation is avoided. Early administration of vasopressors and inotropes are indicated for correction of hypotension and shock [14]. Treatment measures are targeted to augment the supply and decrease the demand for myocardial oxygen. These include oxygen supplementation, maintenance of adequate hematocrit, avoidance of acidosis, reduction in the RV afterload using specific pulmonary vasodilators like inhaled nitric oxide and reducing RV volume load by dieresis and/or ultrafiltration in refractory cases [14]. Our patient received a fluid resuscitation of

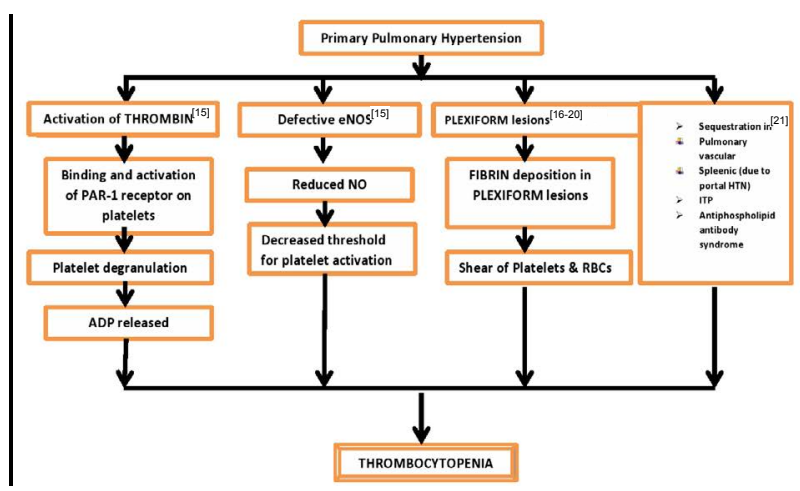

Figure 3: Pathogenesis of Thrombocytopenia in pulmonary hypertension.

$500 \mathrm{ml}$ followed by early administration of Noradrenaline (to increase the coronary perfusion pressure), Dobutamine (to support the compromised RV), pulmonary vasodilators-Sildenafil and Bosentan (to reduce $\mathrm{RV}$ afterload) and oxygen supplementation. We were unable to use $\mathrm{NO}$ as it was not available with us and inhaled prostacyclin was not considered because of thrombocytopenia. We transfused one unit of single donor platelet though there was no evidence of bleeding clinically in view of decreasing trend of platelet count (38000 to 20000/cc).

The possible pathogenic mechanisms for thrombocytopenia in our patient are as described (Figure 3). Blood flow through the pulmonary vasculature in presence of $\mathrm{PH}$ can lead to activation of thrombin which binds to protease-activated receptor-1 (PAR1) on platelets. It leads to platelet degranulation and release of factors like adenosine diphosphate (ADP) leading to platelet aggregation [15]. Nitric oxide (NO) prevents premature activation of platelets. Due to defective endothelial nitric oxide synthases (eNOS), the production of NO is decreased in idiopathic $\mathrm{PH}$. It causes a decreased threshold for platelet activation in patients with idiopathic $\mathrm{PH}$ [15].

Pathological "Plexiform" lesions in vasculature of lung have been described in patients of idiopathic $\mathrm{PH}$. Fibrin deposition occurs in these plexiform lesions. Red blood cells (RBCs) and platelets experience injury to their cell membranes while passing through these lesions leading to increased cell damage [16-19]. Moreover, concurrent association of diseases such as portal hypertension leading to splenic sequestration, idiopathic thrombocytopenic purpura (ITP) and antiphospholipid antibody syndrome may present with thrombocytopenia along with idiopathic PH [20].

\section{Conclusion}

$\mathrm{PPH}$ presenting with thrombocytopenia though rare and reported anecdotally, they are known to have worse prognosis. Other causes of possible thrombocytopenia needs to be excluded prior to concluding idiopathic $\mathrm{PH}$ as the cause for it. The treatment modality for $\mathrm{PH}$ is still not clearly defined.

\section{References}

1. Simonneau G, Gatzoulis MA, Adatia I, Celermajer D, Denton C, et al. (2013) Updated Clinical Classification of Pulmonary Hypertension. J Am Coll Cardiol 62: $34-41$

2. Simonneau G, Robbins IM, Beghetti M, Channick RN, Delcroix M, et al. (2009) Updated clinical classification of pulmonary hypertension. J Am Coll Cardiol 54: S43-54.

3. Nichols WC, Koller DL, Slovis B, Foroud T, Terry VH, et al. (1997) Localization of the gene for familial primary pulmonary hypertension to chromosome $2 q 31$ 32. Nat Genet 15: 277-280. 
4. Thenappan T, Shah SJ, Rich S, Tian L, Archer SL, et al. (2010) Survival in pulmonary arterial hypertension: a reappraisal of the NIH risk stratification equation. Eur Respir J 35: 1079-1087.

5. Li W, Dunmore BJ, Morrell NW (2010) Bone morphogenetic protein type II receptor mutations causing protein misfolding in heritable pulmonary arterial hypertension. Proc Am Thorac Soc 7: 395-398.

6. Denton CP, Black CM (2003) Pulmonary hypertension in systemic sclerosis Rheum Dis Clin North Am 29: 335-349.

7. Almodovar S, Hsue PY, Morelli J, Huang L, Flores SC (2011) Pathogenesis of HIV-associated pulmonary hypertension: potential role of HIV-1 Nef. Proc Am Thorac Soc 8: 308-312

8. Farmakis D, Aessopos A (2011) Pulmonary hypertension associated with hemoglobinopathies: prevalent but overlooked. Circulation 123: 1227-1232.

9. Haddad F, Hunt SA, Rosenthal DN, Murphy DJ (2008) Right ventricular function in cardiovascular disease, part I: Anatomy, physiology, aging, and functional assessment of the right ventricle. Circulation 117: 1436-1448.

10. Haddad F, Doyle R, Murphy DJ, Hunt SA (2008) Right ventricular function in cardiovascular disease, part II: pathophysiology, clinical importance, and management of right ventricular failure. Circulation 117: 1717-1731.

11. van Wolferen SA, Marcus JT, Westerhof N, Spreeuwenberg MD, Marques KM et al. (2008) Right coronary artery flow impairment in patients with pulmonary hypertension. Eur Heart J 29: 120-127.

12. Rich JD, Shah SJ, Swamy RS, Kamp A, Rich S (2011) Inaccuracy of Dopple echocardiographic estimates of pulmonary artery pressures in patients with pulmonary hypertension: implications for clinical practice. Chest 139: 988-993.
13. Galiè N, Hoeper MM, Humbert M, Torbicki A, Vachiery JL, et al. (2009) Guidelines for the diagnosis and treatment of pulmonary hypertension: the Task Force for the Diagnosis and Treatment of Pulmonary Hypertension of the European Society of Cardiology (ESC) and the European Respiratory Society (ERS), endorsed by the International Society of Heart and Lung Transplantation (ISHLT). Eur Heart J 30: 2493-2537.

14. Shah SJ (2012) Pulmonary hypertension. JAMA 308: 1366-1374.

15. Aytekin M, Aulak KS, Haserodt S, Chakravarti R, Cody J, et al. (2012) Abnormal platelet aggregation in idiopathic pulmonary arterial hypertension: role of nitric oxide. Am J Physiol Lung Cell Mol Physiol 302: 512-520.

16. Jubelirer SJ (1991) Primary pulmonary hypertension. Its association with microangiopathic hemolytic anemia and thrombocytopenia. Arch Intern Med 151: 1221-1223.

17. Fischer EG, Marek JM, Morris A, Nashelsky MB (2000) Cholesterol granulomas of the lungs associated with microangiopathic hemolytic anemia and thrombocytopenia in pulmonary hypertension. Arch Pathol Lab Med 124: 18131815

8. Stuard ID, Heusinkveld RS, Moss AJ (1972) Microangiopathic hemolytic anemia and thrombocytopenia in primary pulmonary hypertension. $\mathrm{N}$ Engl $J$ Med 287: 869-870.

19. Bjornsson J, Edwards WD (1985) Primary pulmonary hypertension: a histopathologic study of 80 cases. Mayo Clin Proc 60: 16-25.

20. Horn EM, Barst RJ, Poon M (2000) Epoprostenol for treatment of pulmonary hypertension in patients with systemic lupus erythematosus. Chest 118: 12291230. 